\title{
Reducing water and energy footprints via dietary changes among consumers
}

\author{
D. L. Marrin \\ Water Sciences \& Insights, Encinitas, California, USA 92023
}

Email address:

marrin@watersciences.org

To cite this article:

D. L. Marrin. Reducing Water and Energy Footprints via Dietary Changes among Consumers. International Journal of Nutrition and Food Sciences. Vol. 3, No. 5, 2014, pp. 361-369. doi: 10.11648/j.ijnfs.20140305.11

\begin{abstract}
An increasing global demand for food is occurring at the same time that water shortages and energy restrictions are escalating in many parts of the world. Much of the attention thus far has focused on supply side factors that can produce more food with fewer resources. Consumers, whose personal water footprints are dominated by food-related activities that have both direct and indirect energy requirements, control the demand side factors for food. Whereas conserving water and energy has been a sufficient incentive for a limited number of consumers to change their food habits, there is an increasing array of nutritional, financial, health and safety reasons why a larger number of consumers may be willing to modify their diets. These reasons range from avoiding pathogens and synthetic chemicals to increasing life expectancy and saving money on groceries. From the perspective of conserving water and energy resources, reducing the consumption of certain animal products, increasing the consumption plant-based foods, changing the ways that foods are perceived and accessed, and selecting foods that are produced with fewer potential water pollutants are among the most relevant. The projected influence of dietary changes on water and energy savings are restricted to industrialized nations, with considerable attention given to the current situation in California, where a severe drought in an agriculturally productive region has highlighted the interactions among water, energy and food.
\end{abstract}

Keywords: Diet, Footprints, Water, Energy, Efficiency, Foods

\section{Introduction}

Worldwide droughts and the resulting water shortages, in combination with rising energy costs, have been identified as impediments to keeping pace with global food requirements that are projected to increase substantially during the upcoming decades. In addressing this situation, the primary focus has been on developing methods to more efficiently produce food (using less water and energy) or to put more land under cultivation. These strategies are often referred to as "supply side" because they assume a projected rise in food demand and then explore ways to meet it. Less emphasis has been placed on "demand side" strategies that could reduce the amount of food necessary to feed the projected population. Reasons for this strategy bias are often attributed to perceptions that dietary preferences and habits are relatively immutable and that technology has and will continue to solve our food, water and energy challenges.

There is no shortage of alternatives that have been proposed for the demand side of the water-energy-food nexus. Lester Brown [1], author of the "Plan B" series of books, suggests that among the most pressing needs are controlling global population growth, reversing recent biofuel policies, and decreasing meat consumption in industrialized nations. Similarly, Hoffmann [2] suggests that a predominant focus on supply side factors (e.g., producing more food with fewer resources) and a tacit acceptance of current trends in biofuel production, excessive meat-based diets and food wastage is unlikely to yield permanent solutions.

Although numerous interrelated factors influence the dynamics of a water-energy-food nexus, many of them are either beyond the control of consumers or are perceived to be so. Consequently, this paper focuses on personal dietary changes as means of reducing water and energy footprints. Although not considered in this paper, consumers also have considerable control over the food wastage that contributes to their personal water and energy footprints.

Water and energy footprints can be calculated on a global, national, regional, personal and product basis. The latter 
three bases include the levels at which most individuals perceive an opportunity to affect their water and energy footprints. The emphasis of this paper is on dietary changes among people in the industrialized world, with a number of examples drawn from California where severe water shortages, rising energy costs, diverse dietary habits and an impacted agricultural sector are prevalent.

The recognition that altering one's food choices can reduce water and energy footprints is certainly not a new one. Pro-vegetarian and pro-organic activist groups have been touting meat-free and chemical-free diets as the most sustainable and environmentally friendly for decades. Surveys suggest that people are genuinely interested in conserving the quality and quantity of water and other resources, but they rarely cite food habits as an effective means of doing so [3]. In addition to changing diets for primarily altruistic reasons, consumers are increasingly considering changes in their diet based on health, finances and food safety.

\section{Food and Footprints}

\subsection{Footprints and a Nexus}

The concept underlying a footprint is that everything produced, consumed or utilized by humans requires inputs from the natural world (usually as resources) that can be quantified as a means of assessing their inherent demands. Initially, ecological footprints were developed to estimate the area of biologically productive lands or waters required to produce and dispose of the products. Since their introduction the early 1990's, footprints have been applied to energy, water, carbon and related aspects of the natural world. As such, footprints serve to quantify the embedded resources in products that, when traded or sold, constitute a virtual exchange of those resources. Virtual or imbedded water and energy can be imported, exported, wasted or utilized locally.

A water footprint is defined as the amount of water that is consumed (i.e., no longer available for immediate reuse) to generate a product or service [4]. An internal footprint of a region refers to the water required to generate products within that region (whether exported or utilized locally), while an external footprint is the water required to produce imported goods. Personal water footprints include the total volume of water embedded in goods and services consumed, whether produced locally or imported. A product's water footprint represents the total volume of water required by the cumulative natural and anthropogenic processes that are required to create or transform it.

Similarly, an energy footprint approximates the amount of energy (most often electrical) required to create a product or service. Because electricity is derived predominantly from the burning of fossil fuels, energy footprints may also be expressed as carbon footprints. The quantification of water and energy footprints is a relatively complex process for many reasons, not least of which is that water and energy are mutually dependent on each other in a relationship often referred to as a nexus, which is exemplified by the following food-related example.

One of the largest uses of electricity for food is the indirect use of power in transporting water over long distances to support agricultural irrigation in arid regions. For example, the Central Valley of California produces about half of all the fruits, vegetables and nuts grown in the USA [5], yet most of the water used to irrigate the food crops must be pumped from elsewhere in the state. Fuels used to power the electric pumps require more water, creating a positive feedback loop that escalates both water and energy use.

\subsection{Water Footprints}

Worldwide, about $90 \%$ of personal water footprints are devoted to food in the form of crop and animal production. By contrast, domestic water supply and industrial product contributions are relatively small [6]. Total water footprints include the sum of three types of water. Green water is the rainfall directly consumed by food crops or by grasses that feed grazing animals. The more familiar blue water includes lakes, rivers and aquifers that serve as sources for domestic, industrial and irrigated agriculture use. Finally, gray water represents the volume required to dilute contaminants produced by agricultural, industrial, and residential uses to concentrations that meet water quality standards for human health or the environment.

Food production is usually dominated by green water, except in arid regions where blue irrigation water is a major contributor. The total water footprint of foods varies widely based on how they are grown, processed and transported, as well as their trophic level (e.g., plant or animal) and generation of pollutants. Generally, vegetables (leaves and roots) require the least water per unit weight or mass of food, followed by fruits, grains and nuts, and finally by animal products, oils and specialty foods (e.g., chocolate) that require the most water (Table 1). Among the animal-based foods, beef has the largest water requirement, followed by sheep, pork, poultry, eggs and milk [7,8].

The water requirements of fish vary widely depending on whether they are freshwater or marine and farmed or wild. Farmed freshwater fish have the largest water footprint, whereas wild marine fishes have the smallest. Gephardt et al. [9] evaluated the total water footprint of marine fish by comparing it to the amount of land-based protein necessary to replace fish. The smaller water footprint of marine protein could result in global freshwater savings of almost $5 \%$, but regional savings could reach $50 \%$. Unfortunately, overfishing of the oceans is already a global problem and fish represent less than $17 \%$ of the animal protein $(6.5 \%$ of the total protein) consumed worldwide [10].

Organic food is grown without the use of chemical pesticides, herbicides and fertilizers, yielding a gray water footprint that is substantially lower (as much as 98\% for soybeans) than that of conventional agriculture [11]. In addition, organic farming utilizes cultivation and 
composting techniques that reduce soil evaporation, thus conserving green and/or blue water. Based on total water footprints for 250 foods, an average of $15 \%$ less water was required for organic than for conventional production [12].

\subsection{Energy Footprints}

Similar to the green, blue and gray water footprints, energy footprints are often expressed in terms of the amount of electricity or fuel used to produce different foods. About $20 \%$ of the world's energy footprint is dedicated to food [13], and $17 \%$ of the USA's total fossil fuels are used for food production [14]. The latter figure does not include personal transportation (e.g., cars, buses, trains) required to access food and relocate it to where it is consumed. Surprisingly, one of the largest indirect energy uses associated with food production is the manufacturing of nitrogen fertilizers [15], which are used extensively in conventional farming.

Based on the production of a unit weight of food, grains are least energy-consumptive and beef is the most (Table 1). Producing a kilogram of beef requires more than 70 times the amount of electricity (measured in kilowatt-hours) of producing a kilogram of corn. Pork requires about 2.5 times less electricity to produce than does an equal mass of beef, where as chicken, cheese and eggs require 4 to 8 times less electrical energy than does an equal mass of beef. Finally, a kilogram of apples requires almost 20 times less electricity to produce than does a kilogram of beef. Even on a caloric basis, grains require the least input of electricity and meat products (especially beef) require the most [16].

Table 1. Approximate volume of water (in liters) and electrical energy (in kilowatt-hours) required to produce one kilogram various foods. Based on data presented in References 6, 19 and 20.

\begin{tabular}{lll}
\hline Food Type & Water (liters) & Energy (kWh) \\
\hline Lettuce & 130 & --- \\
Potatoes & 250 & --- \\
Apples & 700 & 3.7 \\
Corn (Maize) & 900 & 0.95 \\
Milk & 1100 & 1.6 \\
Ground Nuts & 3100 & --- \\
Eggs & 3300 & 8.8 \\
Chicken & 3900 & 9.7 \\
Pork & 4800 & 28 \\
Cheese & 5000 & 15 \\
Olive oil & 14,500 & --- \\
Beef & 15,500 & 69 \\
\hline
\end{tabular}

Table 2. The power requirements (in BTU per year and kilowatt hours per year per person) for various food-related activities in the USA. Based on data presented in Reference 21.

\begin{tabular}{lll}
\hline Activity & $\begin{array}{l}\text { BTU/year (in } \\
\text { trillions) }\end{array}$ & $\begin{array}{l}\text { kWh/year/person } \\
\text { (in thousands) }\end{array}$ \\
\hline Agricultural Production & 2200 & 2.4 \\
Product Transportation & 1390 & 1.5 \\
Food Processing & 1680 & 1.9 \\
Packaging and Materials & 680 & 0.75 \\
Food Service/Retail & 1050 & 1.2 \\
Household Storage and & 3250 & 3.6 \\
Preparation & & \\
\hline
\end{tabular}

Among the various sectors of food production, the energy required for household storage and preparation is greatest, followed by agricultural production itself. According to 1997 statistics for the USA, processing, transporting and selling food products require less energy, in terms of fuel or electricity, than does growing, storing or preparing it (Table 2). Hence, consumers can have a significant influence on their energy, as well as water, conservation via the ways that they store, prepare and waste food in their own homes.

Organic farming systems have reportedly decreased fossil fuel inputs $15 \%$ to $60 \%$ for common grain and root crops $[17,18]$. Much of the energy savings is related to the absence of commercial fertilizers and pesticides, which represent agriculture's most pervasive environmental pollutants. Energy savings for livestock production of $50 \%$ were reported for organic grass-fed systems compared to similar sized conventional grain-fed systems [17].

\section{Effects of Dietary Changes}

\subsection{Water Use Efficiency}

\subsubsection{World Perspectives}

The influence of different diets on personal water footprints in Western Europe (Figure 1) indicated that the typical current diet is more water consumptive than either the recommended or vegetarian diets, which contain less meat, sugar and crop oils but more fruits, vegetables, grains and roots [22]. The recommended diet was based on guidelines from Germany's nutrition society (DGE). Daily water requirements for the three diets are given in the units of liters per capita; hence, healthy and vegetarian diets decrease the average Western European's food-dependent water footprint by $26 \%$ and $41 \%$, respectively [22].

Figure 2 lists the various foods consumed in China in terms of their weight, dietary energy, and per capita water requirements. Cereals and roots provide people with the most energy (based on calories) and fruits and vegetables provide them with the bulk of their food intake (based on weight); however, animal products require the most water and provide less than $25 \%$ of the dietary calories or bulk food intake [8]. Fruits and vegetables are the most water-efficient in terms of food weight and grains and roots are the most water-efficient in terms of dietary energy; the difference is due, in part, to the high percentage of indigestible fiber in vegetables. Crop oils and sugar are less water-efficient than either fruits and vegetables or grains and roots, but are more so than animal products.

Another study focused on effects of diet changes in the Mediterranean region, where about $91 \%$ of personal water footprints are devoted to agricultural products and half of those products are represented by meat and dairy [23]. The vegetal-based calories ranged from just over $65 \%$ to almost $90 \%$ in the diets, with North African and Middle Eastern nations at the high end of the range and European nations at the low end. Generally, green water represented the largest fraction of the water footprint $(>80 \%)$, with the remainder 
composed primarily of blue water in arid nations and of gray water in more humid or industrialized nations.

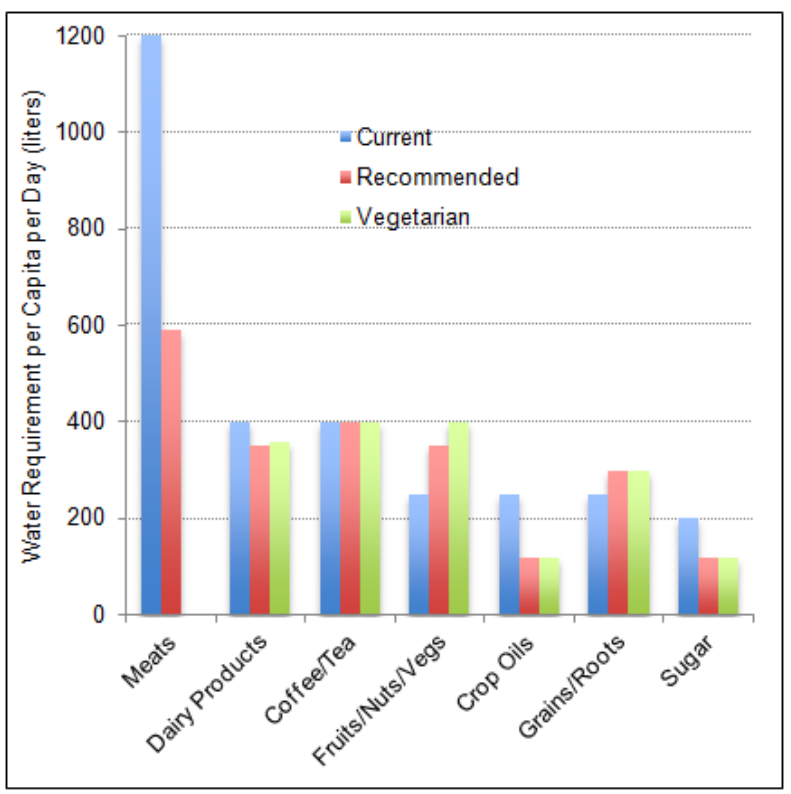

Figure 1. Per capita water requirements (in liters per day) for selected components of current, recommended and vegetarian diets in Western Europe. Based on data presented in Reference 22.

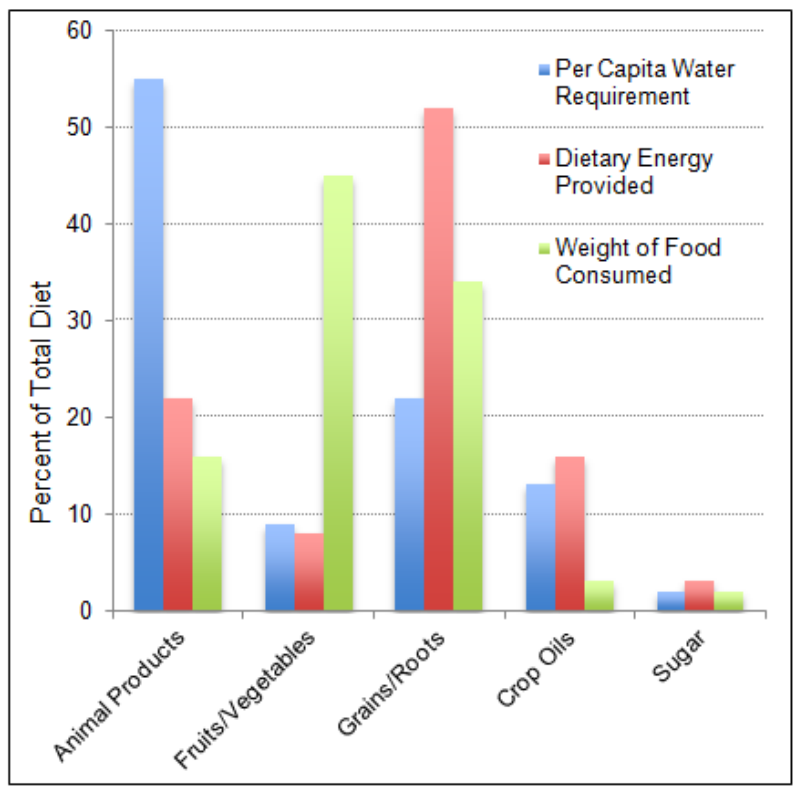

Figure 2. Percent of the average diet in China represented by selected components in terms of their weight, dietary energy and per capita water requirement. Based on data presented in Reference 8.

\subsubsection{A California Perspective}

An article in a small California newspaper recently noted that residents are reducing their water use around the house to cope with the record drought, but that the proverbial elephant in the room is an excessive meat diet that requires one-third of the world's agricultural water [24]. The single largest use of both blue and green water in the state is producing various types of animal feed [4].

Although California is a net importer of total virtual water (largely due to green water imports as foods), it is a net exporter of blue water [4]. Paradoxically, blue water is crucial because it includes the bulk of the depleted, local water resources. Most of the gray water in a Californian's footprint is imported, and about $40 \%$ of it is associated with food products. By contrast, a Californian's blue-green water footprint is dominated by food $(93 \%)$, of which meat and dairy products comprise just over half [4].

Whereas the direct use of water in residences accounts for just 5\% of a Californian's blue-green water footprint [4], reducing the direct use of water conserves local resources (mostly blue water). Dietary changes conserve both blue and green water, some of which is imported and, therefore, not dependent upon local resources. Nonetheless, about 56\% of the blue water in a Californian's blue-green footprint is local, compared to less than $20 \%$ of the green water (Figure 3 ). Because $93 \%$ of the blue-green footprint is food-related, changes in a Californian's diet (demanding the majority of the state's blue water) could conserve more local supplies than cutbacks in their residential water use.

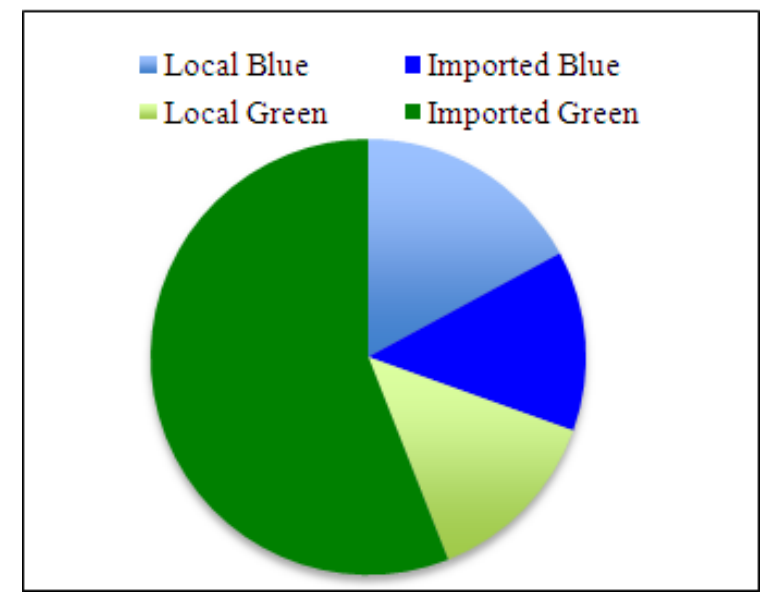

Figure 3. Relative composition of the blue-green water footprint of Californians (in million acre-feet per year) for products and services consumed within the state. Based on data presented in Reference 4.

\subsection{Energy Use Efficiency}

In addition to the aforementioned production of nitrogen fertilizers, which can account for as much as $65 \%$ of the energy required on-farm to produce high yield crops, the use of electricity to pump groundwater (blue water) and convey it to the crops can represent the single largest use of agriculture-related energy in arid regions [15]. This energy cost frequently has been overlooked in regions where governments have subsidized the price of electricity for agriculture. As a result, the mining and overdraft of aquifers requires ever more energy for pumping. Table 3 lists the volume of water required to produce a kilogram of five different fuels used to power the water pumps.

Whereas changes in irrigation efficiency can conserve water and realize energy savings of $20 \%$ to perhaps $50 \%$ [25], people foregoing meat consumption (e.g., substituting grains or roots) could achieve similar energy savings without the costs of purchasing and installing upgraded 
irrigation systems. Obviously, it is unrealistic to expect entire populations to embrace a vegetarian diet (or every farm to replace its irrigation systems), but people's foregoing meat one day per week has been suggested as a starting point [26]. Reducing meat consumption in the Northern Hemisphere by about $33 \%$ has been projected to significantly reduce the stress on global resources [27].

\subsection{Environmental and Safety Concerns}

Besides its high water and energy demands, meat production has been linked to greenhouse gas emissions, water pollutants, global deforestation and perhaps antimicrobial resistance [28,29,30]. Clearing forests to provide short-term pasture for livestock that provide meat to a growing world market has contributed to soil erosion and climate change. Methane and carbon dioxide produced by an increasing number of animals worldwide has exacerbated the latter problem. Another consequence of over-consuming animal products is the proliferation of factory livestock and farmed fish facilities, which use antibiotics and pesticides to control animal disease and generate concentrated water-soluble wastes that frequently pollute fresh waters.

Despite the environmental impacts and animal rights issues linked to meat production, global consumption is increasing. Recent trends in the USA and EU; however, suggest that meat consumption has remained constant or declined slightly during the last decade [31,32]. Possible reasons given for these trends include fashionable diets, recent food safety concerns, increased prices, dietary health risks and a lack of meat trade ethics.

Persistent drought conditions in the Western USA have increased feed costs and reduced animal numbers, both of which have driven up meat prices. Some of the high-speed meat production techniques designed to keep costs in check have led to greater risks from food borne pathogens [14]. In addition, infectious diseases among animals (e.g., porcine diarrhea and "mad cow" epidemics) and the presence of steroids, antibiotics and pesticides in animal products have dissuaded some people from consuming meat.

Table 3. The water required to produce one kilogram of various fuels. Based on data presented in Reference 33.

\begin{tabular}{ll}
\hline Fuel Type (one kilogram) & Required Water (liters) \\
\hline Coal & 0.95 \\
Natural Gas & 1.6 \\
Crude Oil & 3.7 \\
Unconventional Oil & 8.8 \\
Biofuels & 9.7 \\
\hline
\end{tabular}

\section{Nutritional Considerations}

\subsection{Protein Intake}

A common concern about reducing meat intake is the possible lack of sufficient protein and, especially, digestible complete proteins (containing adequate proportions of all the essential amino acids) in one's diet. In fact, the typical Western diet includes about twice the recommended protein of 0.8 grams per kilogram of body weight [34] or 50 grams [35], attributable to a diet containing a high percentage of animal products. Although no consensus has been reached on whether there are detrimental effects associated with consuming excess protein, potential effects linked to the source of that protein is another matter.

Animal, as opposed to plant, protein sources have been linked to the increased incidence and associated mortality of diseases such as stroke, cancer, diabetes, and cardiovascular disease [36,37]. Increased rates of these chronic diseases were formerly attributed only to the animal fats (particularly in red meats), but other components of the meat and chemicals produced by processing and cooking it have been implicated [37,38]. The medical costs associated with meat consumption were estimated in 1992 to be in the range of $\$ 30$ to $\$ 60$ billion USD [39], and per capita health care costs in the USA have tripled since then.

Plant-based proteins eaten in combination can provide an adequate protein source and offer several nutritional benefits, which include dietary fiber, antioxidants, and phytochemicals [40]. Hence, switching to a diet with lesser quantities of meat or animal products is not problematic from a current nutritional perspective. Even conservative organizations such as the American Dietetic Association have taken the position that appropriate vegetarian or vegan diets are healthful, nutritionally adequate and associated with a decreased incidence of hypertension and diabetes compared to conventional Western diets [40].

\subsection{Fats and Carbohydrates}

When comparing the nutrition of meat and meatless diets, sufficient protein is not the only question that arises. Another is the controversial question of whether fats or carbohydrates should provide most of the dietary calories for a Western population beset by obesity. According to the National Institutes of Health [41], obesity ranks second (behind smoking) as a cause of preventable death and a serious risk factor for many chronic diseases. For several decades, the prevailing dietary recommendation to avert or reverse obesity was restricting fats (especially saturated fats). The more recent success of "low-carb" diets has shifted the focus to restricting sugars and grains, which have also been linked to conditions ranging from obesity and diabetes to inflammation and cognitive impairment [42].

The relevance of this ongoing debate to the present topic is that dietary fats traditionally have been associated with the consumption of meat. Although the causative role of dietary fats (including the saturated fats in meat) in disease was likely overstated in the past, the link between meat consumption and health problems is no longer restricted to fats. Moreover, essential fats or lipids in the human diet are not solely components of meat, but are also present in a variety of plants (e.g., as seeds, nuts or fruits) and in marine organisms other than fish (e.g., krill, algae).

A Mediterranean diet endorsed by the Mayo Clinic [43] includes occasional red meat (a few days per month), seafood as the primary meat, poultry and dairy as secondary 
animal products, and a mixture of vegetables, whole grains, fruits, beans, nuts, legumes, seeds and olive oil as the diet's base. This is typical of diets that strike a compromise between "low-fat" and "low-carb" alternatives in restricting beef and pork while emphasizing plant-based foods and moderate portions of fish, poultry and dairy products. Such diets call for a greater reduction in meat consumption (especially red meat) than do the previously discussed recommendations for conserving global resources.

\subsection{Alternative Foods}

In order for changing food choices and diets to be a viable means of conserving water, energy or other limited resources, the options available to people in making the shifts must be acceptable on a personal, financial, and environmental basis. With respect to meat, an often-cited recommendation is that people consume animals that are free range, drug-free and fed their natural foods. In essence, this advice addresses concerns with factory-farmed livestock and fish in which the animals are confined to crowded, unsanitary enclosures and fed mixtures of meats, grains and various additives. Absent a marked decrease in global meat consumption, it is questionable whether sufficient land and aquatic habitat are available for every meat eater to access free range, grass-fed, naturally raised or wild animals.

Factory animal facilities were initially developed to increase profitability and to provide affordable meat and animal products without substantially increasing the area of rangeland. Livestock production already accounts for $70 \%$ of all agricultural lands and $30 \%$ of the planet's land surface [13]. Also, most of the genetically modified corn and soybeans grown worldwide are fed to factory-farmed animals. Hence, the overconsumption of animal products has ramifications beyond just the issues of water and energy efficiency to those impacting the land requirements, availability and nutritional quality of plant-based foods that are consumed by humans.

In addition to dietary changes involving different proportions of meats (or differently produced meats), there is the option of meat substitutes. These substitute proteins include soybeans (tofu and tempeh), grains (quinoa and amaranth), seeds (hemp and buckwheat) and mixtures of beans, rice and lentils. A number of food companies specialize in meat substitutes that are increasingly acceptable to consumers and difficult to discern from real meat [44]. A recent study suggested that consumers' repeated exposure to the unfamiliar meat substitutes led to an increased acceptance; however, if their initial impressions were negative, consumers were less willing to try again [45].

A lack of consistency among organic food standards and a paucity of long-term studies have precluded a consensus on their health benefits; however, there appear to be sufficient data indicating that organic foods contain lower pesticide residues than do conventionally-grown foods [46]. In addition, many organic foods are purchased locally through farmers markets, thus reducing the energy for transportation and, perhaps more importantly, giving consumers the opportunity to conserve local water resources.

\subsection{Eating Habits}

Eating is as much a social and cultural activity as it is a nutritional activity. Traditions, images and habits all play a role in determining one's willingness to change a behavior that many people consider to be an inherent personal right (not unlike water). Lifestyle changes induced by the threat of external consequences depend on whether people are just concerned or truly worried [47]. The latter will often lead to changes, whereas the former will not. If people observe or truly believe that eating certain foods jeopardizes their health, they may actually eat less or try substitutes; however, they are less likely to do so for reasons that do not perceptibly affect them (e.g., climate change, environmental degradation, or the inhumane treatment of animals).

Although it is difficult to separate out the many reasons that people choose the foods in their diet, one of the most influential may be price, which exerts an immediate financial effect. The trend of substituting poultry for beef in the EU during the last 30 years may be cost related [32], reflecting the greater resource demands of beef. By contrast, the average cost of organic foods is $10 \%$ to $85 \%$ higher than conventional foods $[48,49]$, yet their sales in the USA and EU have more than doubled in the last decade. Level of education and prior purchasing of organics are major factors in consumers buying organic food, which is so popular in the USA and EU that cost is cited as the main reason for people not buying them $[49,50]$.

Reisch [51] suggested a number of reasons that sustainable food consumption has been difficult to achieve in industrialized nations. Factors that are particularly germane to the present discussion include a decline in time spent on nutrition (i.e., more processed and fast food), the complexity of food choices (i.e., more products, health claims and controversies) and the resulting confusion and indifference that consumers often experience. These factors, combined with mega-budget advertising campaigns for food products, suggest that education alone may not be sufficient to alter food choices.

The question remains as to who is responsible (if anyone) in shifting diets to support better health and the conservation of resources. One view is that consumers are ultimately responsible because their dietary habits create the demand for foods that producers and retailers attempt to profitably fulfill. Another view is that government agencies should adopt policies requiring producers and retailers to adopt practices that promote better public health and food sustainability. Governments have typically refrained from doing so, except to address food safety issues [51], which is unlikely to change. Thus, consumers will probably have to initiate dietary shifts.

\subsubsection{Californian's Eating Habits}

According to a 1995 survey [52], Californians identified health concerns as having the greatest influence over what 
they eat. Although they expressed a willingness to adopt new dietary strategies to improve their health (e.g., consume more fruits and vegetables), only a fraction of the respondents actually did so. Whereas California is home to some of the nation's most popular vegan restaurants and trendy vegetarian diets [53], only about $8 \%$ of Californians and $5 \%$ of Americans are strict vegetarians.

The record drought has prompted California water managers to impose harsh conservation measures on the state's residents. It will be interesting to observe whether shifting diets provide an alternative to eliminating water use activities that people enjoy. Though authorities are unlikely to target food choices as a means of conserving water, savvy consumers could offer it as an alternative. Considering dietary changes as a means of coping with drought conditions would certainly expand the recognition of food as the major component of personal water footprints.

\section{Conclusions}

\subsection{Footprint Reductions}

Food comprises about $90 \%$ of a person's consumptive water use. While most of the water required for agricultural products is green, irrigated agriculture and highly polluting farm-related practices substantially increase the blue and gray contributions, respectively. People living in industrialized nations have a typical diet that includes meat at twice the recommended levels, resulting in chronic health problems. Meat and many animal products are extremely water inefficient compared to vegetables, grains, fruits and nuts. Whereas meat consumption is increasing globally, trends in the USA and EU suggest a leveling off of demand and a pervasive switch from beef to poultry, which has resulted in some increases in water efficiency.

Food comprises a smaller percentage of energy than water footprints; hence, the effect of dietary changes on total energy footprints is somewhat less. Similar to water, beef is the least energy-efficient food when computed on a weight or caloric basis, and other meats (especially pork) and animal products (except milk) are less energy efficient than plant-based foods. Organic farming practices usually produce greater savings for energy than for water footprints because chemical fertilizers and grain-based animal feeds are extremely energy-inefficient compared to their alternatives. While not directly affected by changing diets, the storage and preparation of food have substantial energy requirements that are related, in part, to food choices.

Adherence to diets currently recommended in many industrialized nations could decrease water and energy footprints by $20 \%$ to $35 \%$. In fact, diets recommended on the basis of improving health often call for greater decreases in meat consumption than those recommended on the basis of conserving resources. Vegetarian diets would decrease energy and water footprints further, but a relatively small percentage of Westerners are vegetarians. From a nutritional perspective, increasing the percentage of plant-based foods in the diets of people in industrialized nations is not problematic and, in fact, could address several costly health issues.

\subsection{Dietary Changes}

Focusing on supply side goals (i.e., producing food using fewer resources) to the exclusion of demand side goals is increasingly impractical in light of climate change, population growth and food-related health issues. With respect to dietary changes initiated by consumers, the most effective are reducing meat consumption, substituting animal-based protein with plant-based protein, limiting the intake of sugar, simple carbohydrates and certain crop oils, and buying organic food when affordable. Although producing organic foods is quite profitable, the yields can be lower than those of conventional food production and there is currently a limited amount of land under organic cultivation [54].

From the perspective of increasing water and energy efficiency, reducing the consumption of meats (particularly red meat) would yield the greatest return. Meats and animal products produced under natural, rather than factory farm, conditions will likely require a decrease in total meat consumption. Increasing the consumption of wild fish may be feasible in some regions, but the recent decline of ocean fisheries suggests that they cannot replace terrestrial meat sources.

Reducing meat intake is not the only dietary change that would generate an increase in energy and water use efficiency (others include eating more locally-grown, raw, organic or unprocessed foods). Nonetheless, the secondary and tertiary effects of meat production are so numerous that realistically calculating the water and energy demands (particularly for gray water) is very difficult. Some of the recommended replacements for meat, such as olive oil (substituting for animal fats), have water footprints almost as large as that of beef on a gravimetric basis; however, the amount of oil consumed per capita is much less.

Consumers in arid regions who often possess a large blue water component in their water footprint can assist in conserving local water resources by purchasing local foods that are grown efficiently with respect to both energy and water. Buying imported food is also an option, but if the exports have a large blue water content (and the associated energy costs for irrigated agriculture), the water scarcity is simply relocated. Because water and energy are interrelated on many levels, shifts in diet or food purchases designed to address one resource often addresses the other.

\subsection{Consumer Unknowns}

Whether sufficient incentives in the form of health benefits, cost savings, safety concerns and trendy foods exist to initiate a large-scale change in the diets of people living in the industrialized world is unknown. Even if one-third of the population reduced their meat consumption by $50 \%$, we would be halfway to achieving the resource conservation goal specified by some of the predictive models. One of the 
arguments against doing so is that models are frequently wrong and tend to overestimate the consequences of our actions or inactions. While this argument has some merit, affluent people residing in industrialized nations eat a disproportionate amount of the meat produced in the world, and their overall consumption patterns are a major driver of water problems and food shortages on both local and global scales [55].

Though governments and international organizations will probably not develop or enforce policies that restrict people's food habits, setting caps on the exploitation of specific natural resources (based on maximum sustainable levels) has been suggested as a method to reduce overconsumption [56]. For example, blue water footprints are seasonally exceeded for half of the world's river basins, which could be addressed by limiting the total water withdrawals that, in turn, could force producers and/or consumers to make more water-efficient choices. Whether this kind of indirect approach to changing dietary habits would succeed is unknown.

A recent evaluation of virtual water and its global trade concluded that population, gross domestic product and geographical distance between trading partners are the major controllers, rather than organized efforts to balance the unequal distribution of global water resources [57]. Wealthy importers, not agricultural exporters, control the worldwide flow of water embedded in products (mostly food). These findings certainly do not mandate that consumers in industrialized nations change their dietary habits, but their doing so would have a significant influence on conserving global water and energy resources.

\section{References}

[1] L. Brown, Full Planet, Empty Plates: The New Politics of Food Scarcity, New York, NY: W.W. Norton, 2012, 144 pp.

[2] U. Hoffmann, "Agriculture at the crossroads," in Trade and Environment Review 2013, Geneva, Switzerland: United Nations Conference on Trade and Development, September 2013, pp. 2-8.

[3] S. Z. Attari, "Perceptions of water use," Proceedings of the National Academy of Sciences, vol. 111(14), pp. 5129-5134, 2014.

[4] J. Fulton, H. Cooley and P. H. Gleick, California's Water Footprint, Oakland, CA: Pacific Institute, December 2012, $47 \mathrm{pp}$.

[5] California Agricultural Statistics Review 2012-2013, Sacramento, CA: California Department of Food and Agriculture, 2013, $131 \mathrm{pp}$.

[6] M. M. Mekonnen and A. Y. Hoekstra, "The green, blue and grey water footprint of crops and derived crop products," Hydrology and Earth System Sciences, vol. 15, pp. $1577-1600,2011$

[7] M. M. Mekonnen and A. Y. Hoekstra, "A global assessment of the water footprint of farm animal products," Ecosystems, vol. 15, pp. 401-415, 2012.
[8] J. Liu and H. H. Savenije, "Food consumption patterns and their effect on water requirement in China," Hydrology and Earth System Sciences, vol. 12, pp. 887-898, 2008.

[9] J. A. Gephart, M. L. Pace and P. D'Odorico, "Freshwater savings from marine protein consumption," Environmental Research Letters, vol. 9, 014005, 2014.

[10] World Review of Fisheries and Aquaculture (Part 1), Rome, Italy: United Nations Food and Agriculture Organization, 2012, 147 pp.

[11] A. E. Ercin, M. M. Aldaya and A. Y. Hoekstra, The Water Footprint of Soy Milk and Soy Burger and Equivalent Animal Products, Delft, Netherlands: UNESCO-IHE Institute for Water Education, February 2011, 29 pp.

[12] S. Hoertenhuber, "Water resources: the gentle cycle is organic," in The Activity Report, Vienna, Austria: FiBL, 2012, pp. 30-31.

[13] H. Aiking, "Future protein supply," Trends in Food Science \& Technology, vol. 22, pp. 112-120, 2011.

[14] L. Horrigan, R. S. Lawrence and P. Walker, "How sustainable agriculture can address the environmental and human health harms of industrial agriculture," Environmental Health Perspectives, vol. 10, pp. 445-456, May 2002.

[15] S. Khan and M. A. Hanjra, "Footprints of water and energy inputs in food production-global perspectives," Food Policy, vol. 34(2), pp. 130-140, 2009.

[16] G. Eshel and P. A. Martin, "Diet, energy, and global warming," Earth Interactions, vol. 10, 17 pp., 2006.

[17] D. Pimentel, Impacts of Organic Farming on the Efficiency of Energy Use in Agriculture, Ithaca, NY: An Organic Center State of Science Review, August 2006, 39 pp.

[18] J. Ziesemer, Energy Use in Organic Food Systems, Rome, Italy: United Nations Food and Agriculture Organization, 2007, 28 pp.

[19] A. Y. Hoekstra, "The water footprint of food," in Water for Food, Stockholm, Sweden: Swedish Research Council for the Environment, 2008, pp. 49-60.

[20] P. Ghanta, "List of foods by environmental impact and energy efficiency," Energy, Environment \& Ideas, truecostblog.com, 24 February 2010.

[21] M. C. Heller and G. A. Keoleian. Life Cycle-Based Sustainability Indicators for Assessment of the U.S. Food System, Ann Arbor, MI: Center for Sustainable Systems, December 2000, 59 pp.

[22] D. Vanham, A. Y. Hoekstra and G. Bidoglio, "Potential water saving through changes in European diets," Environment International, vol. 61, pp. 45-56, 2013.

[23] R. Capone, P. Degs, H. El Bilali, G. Cardone and N. Lamaddalena, "Water footprint in the Mediterranean food chain: implications of food consumption patterns and food wastage," International Journal of Nutrition and Food Sciences, vol. 3(2), pp. 26-36, 2014.

[24] K. Middleton, "Save water the delicious way," East Bay Express, 19 March 2014. 
[25] S. Kulkarni, "Innovative technologies for water saving in irrigated agriculture," International Journal of Water Resources and Arid Environments, vol. 1(3), pp. 226-231, 2011.

[26] A. Morelli, "Eating water," www.angelamorelli.com, 2014

[27] H. Aiking, J. de Boer and J. M. Vereijken, Sustainable Protein Production and Consumption: Pigs or Peas? Dordrecht, Netherlands: Springer, 2006, 45 pp.

[28] WWI Editors, "Meat: now it's not personal!" World Watch Institute Magazine, pp.12-20, July-August 2004.

[29] Antimicrobial Resistance Summary, Geneva, Switzerland: World Health Organization, 263 pp., 2014.

[30] A. Idel, "Livestock production and food security in a context of climate change and environmental and health challenges," in Trade and Environment Review 2013, Geneva, Switzerland: U.N. Conference on Trade and Development, September 2013, pp. 138-153.

[31] Packaged Facts, Meat and Poultry Trends in the U.S., Washington, DC: Market Research Group, no. LA4924214, 2013, 182 pp.

[32] M. Kanerva, "Meat consumption in Europe: issues, trends and debates," Artec-paper no. 187, University of Bremen, January 2013, 58 pp.

[33] Euromoney Energy, Infographics addressing water and fuels, www.euromoneyenergy.com, 2014.

[34] Protein and Health Fact Sheet, Washington, DC: International Food Information Council Foundation, April 2011, 6 pp.

[35] Food and Health in Europe: A New Basis for Action, Geneva, Switzerland: World Health Organization, 2004, 385 pp.

[36] P. Walker, P. Rhubart-Berg, S. McKenzie, K. Kelling and R. S. Lawrence, "Public health implications of meat production and consumption," Public Health Nutrition, vol. 8, pp. 348-356, 2005.

[37] An Pan et. al., "Red meat consumption and mortality," Archives of Internal Medicine, vol. 172, pp. 555-563, March 2012.

[38] R. A. Koeth et al, "Intestinal microbiota metabolism of L-carnitine, a nutrient in red meat, promotes atherosclerosis, Nature Medicine, vol. 19, pp. 576-585, April 2013.

[39] N. D. Barnard, A. Nicholson and J. L. Howard, "The medical costs attributable to meat consumption," Preventative Medicine, vol. 24(6), pp. 646-655, 1995.

[40] W. J. Craig and A. R. Mangels, "Position of the American Dietetic Association: vegetarian diets," Journal of the American Dietetic Association, vol. 109(7), pp. 1266-1282, 2009.

[41] National Institutes of Health, www.obesityresearch.nih.gov., 2014.
[42] D. Perlmutter, Grain Brain, New York, NY: Little, Brown \& Co., 2013, 336 pp.

[43] Mayo Clinic Staff, "Mediterranean diet: a heart-healthy eating plan," Nutrition and Healthy Eating, www.mayoclinic.org, 2 pp., 2014.

[44] S. Strom, "Fake meats, finally, taste like chicken," The New York Times, 3 April 2014.

[45] A. C. Hoek, J. E. Elzerman, R. Hageman, F. J. Kok, P. A. Luning and C. de Graaf, "Are meat substitutes liked better over time? A repeated in-home use test with meat substitutes or meat in meals," Food Quality and Preference, vol. 28, pp. 253-263, 2013.

[46] B. P. Baker, C. M. Benbrook, E. Groth and K. L. Benbrook, "Pesticide residues in conventional, IPM-grown and organic foods: insights from three U.S. data sets," Food Additive and Contaminants, vol. 19(5), pp. 427-446, May 2002.

[47] E. Weber, "Experience-based and description-based perceptions of long-term risk: why global warming does not scare us (yet)," Climate Change, vol. 77, pp. 103-120, 2006.

[48] E. Post and J. Schahczenski, "Understanding organic pricing and costs of production,” ATTRA, 12 pp., November 2012.

[49] C. Dimitri and L. Oberholtzer, "Marketing U.S. organic foods: recent trends from farms to consumers," Economic Information Bulletin, no. 58, 27 pp., September 2009.

[50] Organics and Functional Foods, New York, NY: The Neilsen Company, 4 pp., 2007.

[51] L. Reisch, "The role of sustainable consumption in fostering a fundamental transformation of agriculture," in Trade and Environment Review 2013, Geneva, Switzerland: U.N. Conference on Trade and Development, September 2013, pp. 95-101.

[52] C. M. Bruhn, D. Wong and H. G. Schutz, "Californian's eating habits differ from their dietary attitudes," California Agriculture, vol. 50(5), pp. 22-26, September-October 1996.

[53] J. Gordinier, "Making vegan a new normal," The New York Times, 24 September 2012.

[54] N. Nemes, "Comparative analysis of organic and non-organic farming systems: a critical assessment of farm profitability," in Trade and Environment Review 2013, Geneva, Switzerland: U.N. Conference on Trade and Development, September 2013, pp. 50-55.

[55] J. Hill, "Water for food: international narratives sidelining alternative views," Future of Food: Journal on Food, Agriculture and Society, vol. 1(2), pp. 154-161, 2013.

[56] A. Y. Hoekstra and T. O. Wiedmann, "Humanity's unsustainable environmental footprint," Science, vol. 344, pp. 1114-1117, 6 June 2004.

[57] S. Tamea, J. A. Carr, F. Laio and L. Ridolfi, "Drivers of the virtual water trade," Water Resources Research, vol. 50(1), pp. 17-28, 2014. 